International Journal of Engineering \& Technology, $7(2.23)(2018) 148-151$
International Journal of Engineering \& Technology
SPC
Website: www.sciencepubco.com/index.php/IJET
Research paper

\title{
Calculation of Parameters and Design of the Movable Transfer Station with Vibrating Screen Feeder for the Conveyor System of Deep Queries
}

\author{
Aleksander Sładkowski ${ }^{1 *}$, Arkadiy Yudin², Anatoliy Komissarov ${ }^{3}$, Yuliya Lagunova ${ }^{4}$, \\ Madinur Akhmetova ${ }^{5}$, Ivan Stolpovskikh ${ }^{6}$ \\ ${ }^{1}$ Professor, Silesian University of Technology, Krasinskiego 8, 40-019 Katowice, Poland \\ ${ }^{2}$ Professor, Ural State Mining University, Kuybyshev 30, Yekaterinburg, 620144, Russia \\ ${ }^{3}$ Professor, Ural State Mining University, Kuybyshev 30, Yekaterinburg, 620144, Russia \\ ${ }^{4}$ Professor, Ural State Mining University, Kuybyshev 30, Yekaterinburg, 620144, Russia \\ ${ }^{5}$ PhD student, Kazakh National Research Technical University, Satpayev 22a, Almaty, 050013, Kazakhstan \\ ${ }^{6}$ Professor, Kazakh National Research Technical University, Satpayev 22a, Almaty, 050013, Kazakhstan \\ *Corresponding author E-mail: aleksander.sladkowski@polsl.pl
}

\begin{abstract}
The paper considers a new design of the movable vibrating screen feeder KVG-1PS designed for the reception and transfer of rocks and ores in conveyor complexes of cyclic-and-continuous technology in open-cast mining. It contains the results of design analysis of the new mining machine. The paper represents the technique of establishing the main parameters and the calculation of the movable vibrating feeder on the basis of a cascade shock-absorbing system at the representation of the machine within a three-mass oscillatory system.
\end{abstract}

Keywords: Vibrating Screen Feeder; Mining Machine; Three-Mass Oscillatory System; Cyclic-And-Continuous Technology; Open-Cast Mining.

\section{Introduction}

For mining operations every year there are new difficulties, since most of the relatively simple developments have already been exhausted. For open mining this leads to the need to develop ever deeper careers. Traditional schemes of transportation of rock mass with the help of one mode of transport in this case are not efficient. In article [1] new perspective schemes of rock mass transportation with open mining of minerals are considered. In this case, the most commonly used combined transport: at first mostly the automobile (large capacity dumpers), then the conveyor and finally the railway. In book [2] this kind of transportation was named cyclic-and-continuous technology (CCT).

A set of equipment of conveyor complexes includes a movable device as a single unit - a transfer station (TS). Such TS is mounted above the stacking conveyor and moves along it in compliance with the process requirements. The main disadvantages of existing TSs are the following: high dynamic loads exerted directly onto the receiving conveyor belt due to the absence of a feeder under the bunker, load turbulence as it exits into the area of a trail car, spillages, limited length of a TS depending on the capacity of the cable reel, the impossibility to receive the rock mass.

In heavy quarry conditions, movable TSs are usually equipped with various types of feeders [3]. Due to the fact that the loading of the hopper is not carried out regularly, the feeder task is the metered delivery of the rock mass to the belt of the conveyor. Problems arise when minerals are extracted by explosive method and large stones can be present among the rocks. In this case, grinding of the rock must be carried out before loading onto the conveyor. For example, in Fig. 1 is shown the modern mobile impact crusher [4].

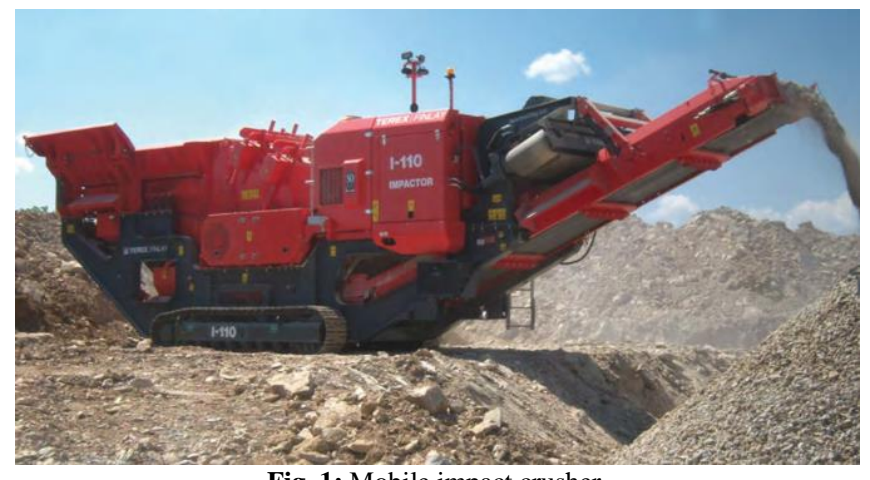

Fig. 1: Mobile impact crusher

\section{Movable transfer stations for the transfer of hard rocks and ores}

With the purpose of correcting the above-mentioned disadvantages the movable vibrating screen feeder KVG-1 PS was manufactured which is designed for the reception and handling of hard rocks and ores in conveyor complexes of the CCT. The screen feeder was developed at the Mining Institute of the Ministry of Ferrous Metal Industry (Russia). It is designed for the application in conveyor transport complexes with a $1.2 \mathrm{~m}$ belt. The machine is installed in transfer stations of mobile conveyors and in feeding places of face conveyors by means of movable crushers or screens. The general view of the vibrating screen feeder is shown 
in Fig. 2. The vibrating screen feeder has the following characteristics: capacity: $1,200 \mathrm{t} / \mathrm{h}$; the largest size of the received cobs: 0.5 $\mathrm{m}$; the loading height: $3.0 \mathrm{~m}$; rock mass interface by classes: \pm 0.2 $\mathrm{m}$; speed of movement: $11.1 \mathrm{~m} / \mathrm{min}$; the number of drive wheels: two; rated capacity: $35 \mathrm{~kW}$; total weight: 20 tons. Type of working element: vibrating screen feeder with directed oscillations, the installation angle: $15^{\circ}$, the oscillation amplitude: $3 \div 4 \mathrm{~mm}$, the vibration angle: $30^{\circ}$. Self-balancing vibration exciters, the number of exciters: two, the oscillation frequency: 960 vibrations/ min, the total disturbing force: $120 \div 160 \mathrm{kN}$, the drive motor power: 30 $\mathrm{kW}$.
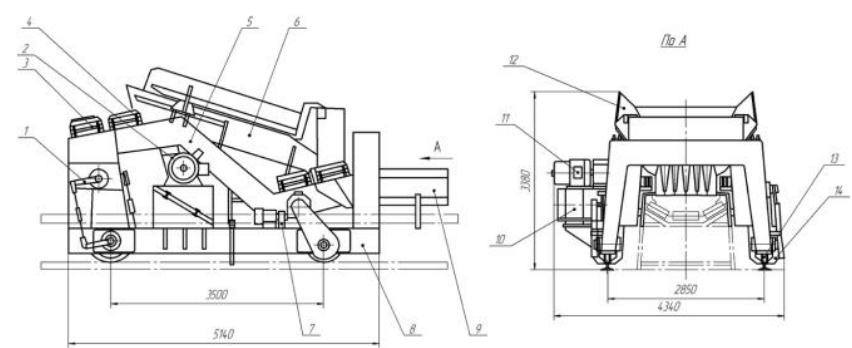

Fig. 2: Movable vibrating screen feeder KVG-1PS for the transfer of rocks

The device consists of the following main units (Fig. 2) [5, 6]: working element 6 with vibrators 2 and the drive 11, the subframe 5 with flanges 12 , the support frame 8 with undercarriages 13 , elastic connections 3 and 4.

The working element of the vibrating screen feeder 6 has a weld assembly which includes a receiving and grate parts. The width of the working element in the discharge part is $1.2 \mathrm{~m}$, in the feed part: $1.04 \mathrm{~m}$. The length of the receiving plate: $1.6 \mathrm{~m}$, the length of grates: $1.6 \mathrm{~m}$. In total there are $5 \mathrm{~T}$-shaped grates. Under the receiving plate, below the working element there is an installed bracket fixing the vibrators. The brackets fixing the elastic elements 4 are welded from the outside to the lateral surfaces of the working element.

The working element is mounted on the subframe 5 through the rubber-metal elastic elements 4 . The frame is welded, hollow and sectional and covers the receiving conveyor. In turn, the frame 5 bears the brackets of elastic ties 3 and through them is mounted on the supporting frame 8 . The base frame also covers a conveyor and bears the driving device 11 with a supporting bracket 10 , the movement mechanism 7 and driving wheels 13 . An anti-theft device 14 , the balancing device 1 , the flanges 9 are mounted on the frame.

The unbalance shafts of vibrators rotate due to the engine through the driveline. Vibrators 2 are connected with each other by a flexible coupling.

The wheels of the device 13 rest on the conveyor rails and move on them using the undercarriage 7 , which includes an engine, a worm reduction gearbox, and a chain transmission. The anti-theft devices 14 are installed in the center of the support frame, one on each side.

The design features of the new mining machine are as follows:

1) The main operating member is the vibrating screen feeder with super-resonance mode of operation. Significant dynamic loads, proportional to the magnitude of the disturbing force of the vibratory drive and stiffness of resilient supports, are transmitted onto the support frame in operation and at the transition through the resonance range. At that, the support frame performs hyperadmissible vibrations. The design embodies the solution ensuring the reduction of support frame's vibrations to acceptable values;

2) The transfer station is a model of the three-mass oscillatory system with the possibility of inertial shock absorption;

3) The screen section of the vibrating screen feeder enables the separation of $\pm 0.2 \mathrm{~m}$ fraction from the hard rock and anticipatory addition of fine fractions onto the receiving conveyor belt before the delivery of large pieces, thereby forming a refractory layer and increasing belt's life time;

4) To reduce resonant vibrations of the transfer stations' units, elastic rubber-metal elements working in shear are used in the design.

\section{The calculation of a movable transfer sta- tion with a vibrating feeder as a model with the inertial shock-absorbing system}

All paragraphs must be justified alignment. With justified alignment, both sides of the paragraph are straight.

\subsection{Text font of entire document}

The entire document should be in Times New Roman. The font sizes to be used are specified in Table 1 .

\subsection{Title and author details}

To reduce dynamic loads from vibration machines on supporting structures the instrument engineering applies the active cascade vibration isolation with two or three degrees of freedom [7, 8]. In the mining engineering there is no practice of installing heavy vibration feeder on movable chassis or is using very rare.

This article sets out the developed method of calculation of parameters and calculation of the movable vibrating screen feeder KVG-1PS based on the theory of cascade shock-absorbing system at the representation of the machine within a three-mass oscillatory system (Fig. 3).

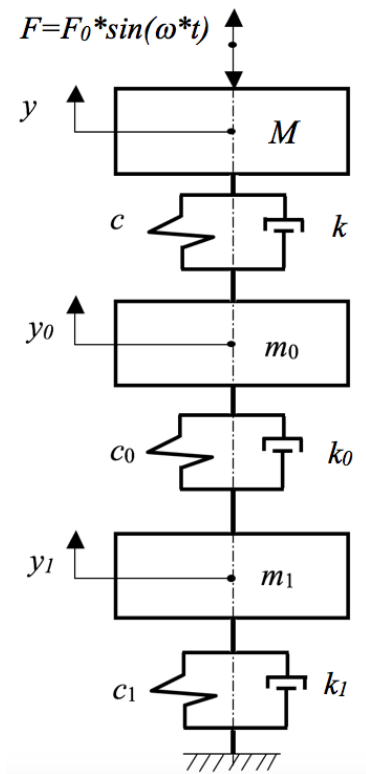

Fig. 3: Design model of the movable screen feeder

The disturbing force Fosin $\omega t$ of vibrators is exerted to the working element at the vibration angle $\beta$, and passes through the inertia mass center $M$. To reduce the vibration amplitude of the support structure with mass $m_{l}$ the cascade system ensures the introduction of additional mass $\mathrm{m} 0$ into the design installed between the masses $M$ and $m_{l}$. The methodology specifies that the disturbing force transmitted through elastic supports $c$ on the mass $m_{0}$ also passes through its center of inertia. The design model provides that elastic centers of elastic supports $c$ and $c_{0}$ are approximately in line. In harmony with the provisions of the vibration theory of vibration isolation systems, the assumptions allow the consideration of the design model of the movable vibrating screen feeder KVG-1PS in the form of a cascade circuit in Fig. 3. The vibrations are considered in the form of the dissipative three-mass system progressively moving in "y" direction. Fig. 3 shows: $M, m_{0}, m_{1}$ are oscillating masses of the working element of the vibrating feeder, 
subframe, the mass of the support structure, respectively; $c, c_{0}, c$ are stiffness coefficients of the main elastic system, elastic system of the subframe, elasticity of soil or elasticity of spring chassis systems, respectively; $k, k_{0}, k_{l}$ are coefficients of damping of elastic systems, respectively.

Having determined expressions of kinetic and potential energies as well as the Rayleigh dissipative function and having substituted their values into the Lagrange equation of the second kind, we come to the following system of differential motion equations of the system shown in Fig. 3:

$$
\begin{aligned}
& m_{1} \ddot{y}+c_{1} y_{1}+k_{1} \dot{y}_{1}+c_{0}\left(y_{1}-y_{0}\right)+k_{0}\left(\dot{y}_{1}-\dot{y}_{0}\right)=0 ; \\
& m_{0} \ddot{y}_{0}+c_{0}\left(y_{0}-y_{1}\right)+c\left(y_{0}-y\right)+k_{0}\left(\dot{y}_{0}-\dot{y}_{1}\right)+k\left(\dot{y}_{0}-\dot{y}\right)=0 ; \\
& M \dot{y}+c\left(y-y_{0}\right)+k\left(\dot{y}-y_{0}\right)=F_{0} \sin \omega t .
\end{aligned}
$$

The particular solution of the system (1) takes the following form:

$$
y_{(1,0, y)}=B_{i} \cos \omega t+B_{j} \sin \omega t \text {. }
$$

Having substituted $y_{i}, \dot{y}_{i}, \ddot{y}_{i}$ into the equations (1) and setting the coefficients before $\sin \omega t$ and $\cos \omega t$ to zero, we arrive at the heterogeneous system of algebraic equations for determining six constants $B_{5}-B_{10}$. Having omitted the writing of the system and its determinant and having noted that at the study of oscillations a a sufficient distance from the resonance it is possible to neglect the members in the equations (1), which characterize the forces of viscous resistance, we write a solution of the determinant in its final form:

$$
\begin{aligned}
& \Delta_{2}=\left(c_{1}+c_{0}-m_{1} \omega^{2}\right)\left[m_{0} M \omega^{4}-\left(c M+c_{0} M+c m_{0}\right) \omega^{2}+c_{0} c\right]- \\
& -c_{0}\left(c-M \omega^{2}\right)
\end{aligned}
$$

The values of the constant coefficients in the system can be written as follows:

$$
\begin{aligned}
& B_{5}=A_{1}=\frac{F_{0}}{\Delta_{2}} c_{0} c ; \\
& B_{6}=B_{8}=B_{10}=0 ; \\
& B_{7}=A_{0}=\frac{F_{0}}{\Delta_{2}} c\left(c_{1}+c_{0}+m_{1} \omega^{2}\right) ; \\
& B_{9}=A=\frac{F_{0}}{\Delta_{2}}\left[\left(c_{1}+c_{0}+m_{1} \omega^{2}\right)\left(c+c_{0}-m_{0} \omega^{2}\right)-c_{0}^{2}\right] .
\end{aligned}
$$

Having accepted the particular solution of the system (1) in the following form

$$
A_{i \max }^{2}=B_{i(n)}^{2}+B_{i(n+1)}^{2},
$$

we arrive at the expressions for the amplitude of the system's forced oscillations. By solving the characteristic equation (3) relative $\omega^{2}$, it is possible to obtain three real roots that determine the system's natural vibration frequencies. Having obtained the first particular solution (5) relative $m_{1}$, we arrive at the formula for the calculation of the supporting frame's (undercarriage) mass at the admissible amplitude of its oscillations and known soil and shock absorbers elasticity:

$$
m_{1}=\frac{1}{\omega^{2}}\left\{c_{1}+c_{0}\left[1-\frac{c\left(F_{0} / A_{1}+1\right)+M \omega^{2}}{m_{0} M \omega^{4}-\left(c M+c_{0} M+c m_{0}\right) \omega^{2}+c_{0} c}\right]\right\} \text {. }
$$

The expression shows that the mass value $m_{1}$ is directly proportional to the soil elasticity and inversely proportional to the square of the frequency of forced oscillations of the working element. In the particular case, when value $c_{1} \gg c_{0}$, the second member of the formula in curly brackets has no significant effect on the undercarriage mass. The unit operation on hard soils requires considerable weights of undercarriages even with the use of vibration-isolated screen feeder. In this case, to reduce the weight the undercarriage or the support of the TS must be equipped with additional shock absorbing elements decreasing value $c_{1}$. It can be achieved by using pneumatic tire run or the supporting base with spring elements.

As an example, the modeling and practical design of the movable vibrating screen feeder KVG-1PS were performed represented by the three-mass system model with the application of Universal Mechanism (UM) 8.1.2 [9] software. We examined the motion of the system at the mass of the working element $M=4,250 \mathrm{~kg}$, the intermediate mass $m_{0}=5,500 \mathrm{~kg}$, the mass of the support frame $m_{1}=10,300 \mathrm{~kg}$. The accepted disturbing power of the vibratory drive equaled $P_{0}=16 \cdot 10^{4}$ or $12 \cdot 10^{4} \mathrm{~N}$ which was harmonic excitation with frequency $\omega=100 \mathrm{~Hz}$. The values of the stiffness coefficients $c$ and $c o$ also varied. It is known that in majority of cases the damping does not have any significant impact on the values of the natural frequencies. Having regard for the fact that the calculation of damping factors of such a complex structure is a complicated task and that, on the other hand, the damping effect in this concrete design is not significant, it was decided not to take damping as the first approximation, therefore coefficients $k, k o, k_{l}$ were set to zero.

Fig. 4 shows eigenmodes of the model under consideration for the minimum rigidity values of elastic elements. At that, the first form of vibration (Fig. 4a) takes place at the natural frequency of 1.674 $\mathrm{Hz}$. In case of this form of vibrations, the upper masses move inphase mainly due to the stretching or compression of the elastic element $c_{0}$. The second form of vibration (Fig. 4b) is achieved at the frequency of $5.296 \mathrm{~Hz}$. The upper masses work in antiphase due to stretching or compression of elastic elements $c$ and $c_{0}$. And finally, the highest third form of vibration (Fig. 4c) is achieved at a relatively high frequency of $22.245 \mathrm{~Hz}$. At this frequency, the lower body makes vertical movement due to deformation of the elastic elements $c$ and $c_{0}$.

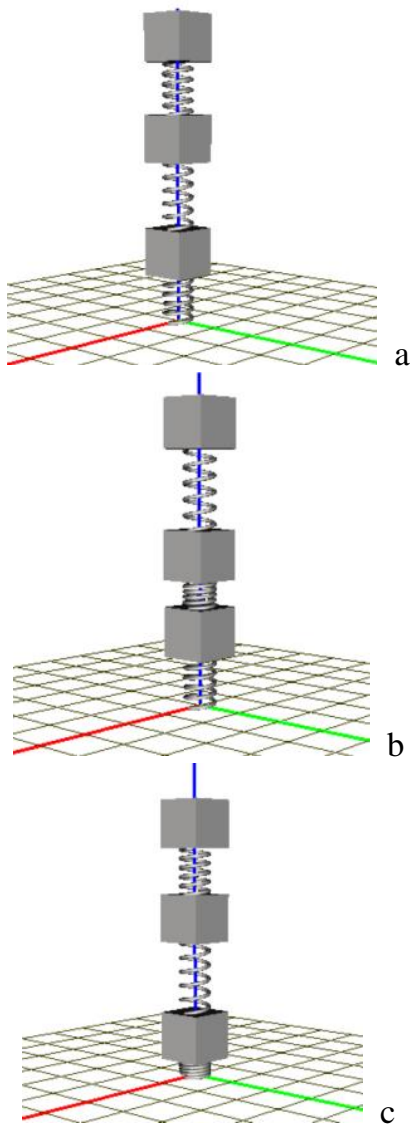

Fig. 4: Eigenmodes calculated for the minimum rigidity values of elastic elements $\left(c=24 \cdot 105, \mathrm{~N} / \mathrm{m} ; c_{0}=12 \cdot 105, \mathrm{~N} / \mathrm{m} ; c_{l}=2 \cdot 108, \mathrm{~N} / \mathrm{m}\right)$

Fig. 5 shows the vertical vibrations of the mass $M$ relative to the proper equilibrium position under the action of a harmonic coercive force Fosin $\omega t$ that is applied to this mass and where $F_{0}=12 \cdot 10^{4} \mathrm{~N} ; \omega=100 \mathrm{~Hz}$. As it is seen in the graph, the movement amplitude is around $20 \mathrm{~cm}$. To compare, there is a graph showing the vibrations of the lower mass under the action of the 
same force (Fig. 6). At that, the amplitude does not exceed 0.1 $\mathrm{mm}$.

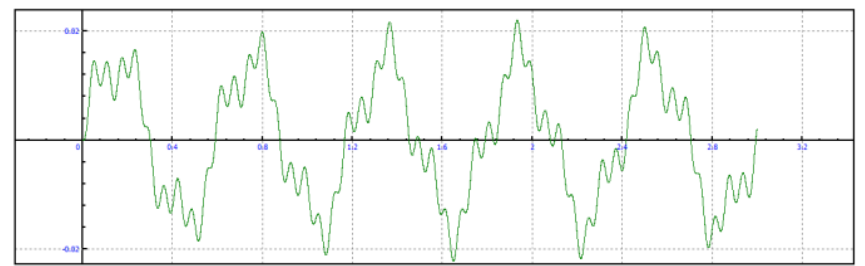

Fig. 5: Vertical movements (m) of the mass $M$ relative to the proper equilibrium position under the action of a harmonic coercive force during the first three seconds

This can be explained only by the fact that the rigidity of the base, which also accounts for the soil hardness, is very high. And this practically leads to immobility of the considered mass which confirms the foregoing theoretical conclusions.

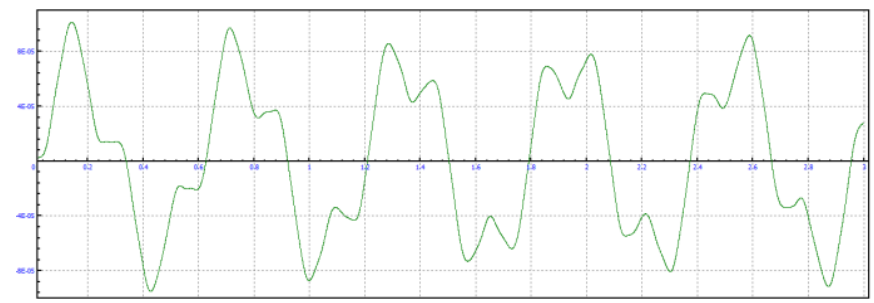

Fig. 6: Vertical movements $(\mathrm{m})$ of the mass $m_{l}$ relative to the proper equilibrium position under the action of a harmonic coercive force during the first three seconds

\section{Conclusion}

The calculation of movable transfer stations based on the vibration machines comes to the motion analysis of the three-mass oscillatory systems. The article contains the analysis of oscillations of such systems and practical calculation of parameters of the mobile transfer station based on the vibrating screen feeder KBG-1PS.

The developed method of calculation of the movable transfer station of the conveyor system with vibrating screen feeder ensures the setting of main parameters of feeders and the research of threemass systems with due account for mining and engineering parameters of hard rocks and ores.

The method is tested at the designing of the movable vibrating screen feeder KVG-1PS and can be used by research and design organizations and industrial enterprises engaged in the designing, manufacturing and operation of s movable transfer stations.

\section{References}

[1] Chen S-Z, Cai Q-X, Zhou W \& Zhang L (2009) Study on new pattern of semi-continuous mining system used in surface mines. Procedia Earth and Planetary Science 1(1), pp. 243-249.

[2] Demirel N \& Karpuz C (2015) Surface coal production methods and equipments. Coal Production and Processing Technology, Riazi MR \& Gupta R (eds.) CRC Press, pp. 149-160.

[3] Hartford CE, Orlando AD \& Carson JW (2013) Feeder or conveyor: what's the difference and why does it matter? Australian Bulk Handling Review, pp. 26-29.

[4] Tracked mobile impact crusher (2017) URL: http://www.terex.in/en/cs/groups/webcontent/@web/@mpdealer /documents/web_content/ucm02_067608.pdf

[5] Юдин АВ (1987) Самоходный вибропитатель-грохот для загрузки конвейеров в комплексах ЦПТ. Горный журнал. 3 pp. 45-48. [In Russian: Yudin AV (1987) A movable screen feeder for loading conveyors in the complexes of the cyclic-and-continuous technology. Mining Journal]

[6] Юдин АВ (2011) Теория и технические решения транспортно перегрузочных систем в карьерах. Екатеринбург: Издательство УГГУ, 507 p. [In Russian: Yudin AV (2011) The theory and tech- nical solutions of the transportation transfer systems in quarries. Ekaterinburg: Publishing house of USMU.]

[7] Finley WR, Hodowanec MM \& Holter WG (2000) An analytical approach to solving motor vibration problems. IEEE Transactions on Industry Applications. 36(5) pp. 1467-1480.

[8] Jiang X, McFarland DM, Bergman LA \& Vakakis AF (2003) Steady state passive nonlinear energy pumping in coupled oscillators: theoretical and experimental results. Nonlinear Dynamics. 33 , pp. 87-102.

[9] Universal Mechanism (2018) URL: http://www.universalmechanism.com/en/pages/index.php?id=1 